\title{
Beneficial effects montelukast, cysteinyl-leukotriene receptor antagonist, on renal damage after unilateral ureteral obstruction in rats
}

Alper Otunctemur ${ }^{1}$, Emin Ozbek ${ }^{2}$, Suleyman Sami Cakir ${ }^{3}$, Murat Dursun ${ }^{4}$, Mustafa Cekmen ${ }^{5}$, Emre Can Polat ${ }^{6}$, Levent Ozcan ${ }^{7}$, Adnan Somay ${ }^{8}$, Nurver Ozbay ${ }^{8}$

${ }^{1}$ Department of Urology, Okmeydani Training and Research Hospital, Istanbul, Turkey; ${ }^{2}$ Department of Urology, Katip Celebi University, Ataturk Training and Research Hospital, Izmir, Turkey; ${ }^{3}$ Department of Urology, Bayburt State Hospital,Bayburt, Turkey; ${ }^{4}$ Department of Urology, Bahcelievler State Hospital, Istanbul, Turkey; ${ }^{5}$ Department of biochemistry, Kocaeli University, , Kocaeli, Turkey; ${ }^{6}$ Department of Urology, Istanbul Medipol University, Faculty of Medicine, Istanbul, Turkey; ${ }^{7}$ Department of Urology, Derince Training and Research Hospital, , Kocaeli, Turkey; ${ }^{8}$ Department Pathology, Fatih Sultan Mehmet Training and Research Hospital, Istanbul, Turkey

\section{ABSTRACT}

Introduction: Ureteral obstruction is a common pathology and caused kidney fibrosis and dysfunction at late period. In this present, we investigated the antifibrotic and antiinflammatory effects of montelukast which is cysteinyl leukotriene receptor antagonist, on kidney damage after unilateral ureteral obstruction(UU0) in rats.

Materials and Methods: 32 rats divided four groups. Group 1 was control, group 2 was sham, group 3 was rats with UUO and group 4 was rats with UUO which were given montelukast sodium (oral $10 \mathrm{mg} / \mathrm{kg} /$ day). After 14 days, rats were killed and their kidneys were taken and blood analysis was performed. Tubular necrosis, mononuclear cell infiltration and interstitial fibrosis scoring were determined histopathologically in a part of kidneys; nitric oxide(NO), malondialdehyde(MDA) and reduced glutathione(GSH) levels were determined in the other part of kidneys. Urea-creatinine levels were investigated at blood analysis. Statistical analyses were made by the Chi-square test and one-way analysis of variance (ANOVA).

Results: There was no difference significantly for urea-creatinine levels between groups. Pathologically, there was serious tubular necrosis and fibrosis in group 3 and there was significantly decreasing for tubular necrosis and fibrosis in group $4(p<0.005)$. Also, there was significantly increasing for NO and MDA levels; decreasing for GSH levels in group 3 compared the other groups $(\mathrm{p}<0.005)$.

Conclusion: We can say that montelukast prevent kidney damage with antioxidant effect, independently of NO.

\section{ARTICLE INFO}

Key words:

montelukast [Supplementary

Concept]; cysteinyl-leukotriene

[Supplementary Concept]; Renal

Insufficiency; Ureteral

Obstruction

Int Braz J Urol. 2015; 41: 279-87

Submitted for publication:

May 14, 2014

Accepted after revision:

July 27, 2014

\section{INTRODUCTION}

Chronic kidney diseases, which lead to end-stage kidney failure, are associated with changes in kidney structure and fibrosis regardless of the underlying cause. Urinary tract obstruction is characterized by tubular atrophy or dilation, tubular cell death by apoptosis and necrosis, interstitial 
leukocyte infiltration, and increased interstitial matrix deposition (1). The acute phase of obstructed kidney in unilateral ureteral obstruction (UUO) is characterized by dramatic changes in glomerular filtration rate, renal blood flow, and interstitial edema $(2,3)$.

Such an obstruction might be observed after benign prostatic hyperplasia; renal, ureteral, or bladder calculi; urethral stricture; and neoplasm of the bladder, prostate, or urethra (1). The hydrostatic pressure, which is the result of the blockage, initiates renal injuries. The injuries are characterized by tubular dilatation or atrophy, inflammatory infiltration of leucocytes, fibroblast activation, proliferation, increase in matrix proteins, and progressive interstitial fibrosis with the loss of renal parenchyma. Unilateral ureteral obstruction (UUO) is an experimental rat model of renal injury that imitates the process of obstructive nephropathy in an accelerated manner(1).

Reactive oxygen species (ROS) are a recently recognized mechanism in the pathogenesis of UUO in experimental studies. Increased lipid peroxidation has been reported in renal cortexes of UUO animals. It has been shown that oxidative stress in UUO contributes to the development of tubulointerstitial lesions and renal fibrosis. Various factors with complex cellular and molecular interactions have also been proposed as possible causes that lead to tubulointerstitial lesions and renal fibrosis (4-7).

Nitric oxide (NO) acts as an intercellular messenger and regulates cellular functions such as vasorelaxation and inflammation. NO has an important role in the elimination of pathogens and tumor cells; however, overproduced NO is oxidized to ROS, resulting in the disruption of cell signaling and uncontrolled systemic inflammation $(8,9)$. Malondialdehyde (MDA) is one of the important markers of lipid peroxidation (10). Excessive MDA produced as a result of tissue injury and DNA damage could combine with free amino groups of proteins, resulting in the formation of MDA-modified protein adducts. Glutathione (GSH) is the major intracellular antioxidant with multiple biological functions, including the maintenance of the thiol moieties of proteins and the reduced from of many other biologically active molecules (11).

Leukotrienes, the products generated by the 5-lipoxygenase pathway are particularly important in inflammation; indeed, leukotrienes increase microvascular permeability and are potent chemotactic agents (12). Moreover, inhibition of 5-lipoxygenase indirectly reduces the expression of TNF-alpha (a cytokine that plays a key role in inflammation), and there are a number of studies demonstrating the role of leukotrienes as mediators of the gastric damage induced by ethanol and some other noxious substances $(13,14)$. Cysteinyl leukotrienes(CysLT), leukotrienes C4, D4, and E4 (LTC4, LTD4, LTE4) are secreted mainly by eosinophils, mast cells, monocytes and macrophages, and they exert a variety of actions which emphasize their importance as pathogenic elements in inflammatory states $(15,16)$.

Montelukast (MK-0476), a selective reversible cys-leukotriene-1 receptor (LTD4 receptor) antagonist is used in the treatment of asthma and is reported to reduce airway eosinophilic inflammation in this disease (17-19). CysLT1 receptor antagonists or biosynthesis inhibitors have been reported to ameliorate ethanol-induced gastric mucosal damage and experimental colitis (13, 20, 21).

Based on these findings, we investigated the antifibrotic and antiinflammatory effects of montelukast on kidney damage after UUO in rats by measuring MDA, NO and GSH levels and the myeloperoxidase activity.

\section{MATERIAL AND METHODS}

\section{ANIMALS}

Male Wistar Albino rats, weighing 200 to $250 \mathrm{~g}$ and 6 to 7 weeks old, were housed in clean plastic cages in a temperature and humidity controlled facility under a constant 12-hour light/12-hour dark photoperiods with free access to food and water. The Institutional Animal Care and Use Committee approved the use of animals and the experimental protocol, and animals were treated in accordance with the Guide for the Care and Use of Laboratory Animals of Research Council. 


\section{TREATMENT AND EXPERIMENTAL PROTOCOLS}

One week after acclimatization, UUO was induced. Briefly after induction of general anesthesia by intraperitoneal injection of thiopental (100 $\mathrm{mg} / \mathrm{kg}$ ), the abdominal cavity was exposed via midline incision and the left ureter was ligated at 2 points with 3-0 silk. The sham-operated rats had their ureters manipulated but not ligated. All rats were given amikacin sulfate $(6 \mathrm{mg} /$ $\mathrm{kg}$, intramuscularly route) before operation. The rats were randomly divided into four groups, each consisting of eight animals. Rats with no operation (Group-1) received no treatment and served as controls. Rats in group 2 underwent unilateral ureteral ligation and received no treatment. Group 3 rats underwent sham operation and received no treatment with montelukast sodium (ML). Rats in Group-4 were subjected to unilateral ureteral ligation and received ML ( p.o. $10 \mathrm{mg} / \mathrm{kg} /$ day) (22).

At 14 days after UU0, all rats were sacrificed by high-dose ketamine. Kidneys were reached with an abdominal midline incision. Left kidney was immediately excised and separated from the surrounding tissues, washed twice with cold saline, and stored at $-80^{\circ} \mathrm{C}$ to determine the levels of renal malondialdehyde (MDA), GSH, and NO. A portion of the left renal tissue was stored in formol solution for the histopathologic examinations. Paraffınized tissue samples were examined for leukocyte infiltration and renal fibrosis. Urea-creatinine levels were investigated at blood analysis. Renal impairment was assessed by serum urea and creatinine levels, as well as by the kidney histology. Serum urea and creatinine levels were determined with an autoanalyzer (Syncron LX20, Ireland) by using commercial Becman Coulter diagnostic kits.

\section{MEASUREMENT OF TISSUE LIPID PEROXIDATION LEVEL}

Frozen kidney samples were homogenized in Teflon-glass homogenizer with a buffer containing $1.5 \%$ potassium chloride to obtain $1: 10$ (w/v) whole homogenate. MDA, which is formed as an end product of the lipid peroxidation, served as an index of the intensity of oxidative stress.
MDA, referred to as thiobarbituric acid reactive substance, was measured with thiobarbituric acid at $532 \mathrm{~nm}$ in a spectrophotometer, as described previously (23). The MDA level was expressed as $\mathrm{mmol} / \mathrm{g}$ wet tissue.

\section{MEASUREMENT OF TISSUE GSH LEVEL}

Reduced GSH was estimated by the method of Moron et al. (24), where the color developed was read at $412 \mathrm{~nm}$. Protein concentrations in all samples were measured using the method of Lowry et al. (25). Results were reported as $\mathrm{mmol} / \mathrm{g}$ wet tissue.

\section{MEASUREMENT OF TISSUE NO LEVEL}

Total nitrite was quantified by the Griess reaction after incubating the supernatant with Escherichia coli nitrate reductase to convert $\mathrm{NO}^{3}$ to $\mathrm{NO}^{2}$. Griess reagent (1 mL 1\% sulfanilamide, 0.1\% naphthyl-ethylenediamine hydrochloride, and 2.5\% phosphoric acid; Sigma Chemicals) was then added to $1 \mathrm{~mL}$ of supernatant (26). The absorbance was read at $545 \mathrm{~nm}$ after 30 -minute incubation. The absorbance was compared with the standard graph of $\mathrm{NaNO}^{2}$, obtained from the reduction of $\mathrm{NaNO}^{3}$ (1-100 mmol/L). The accuracy of the assay was checked in two ways; the inter- and intraassay coefficients of variation were $7.52 \%$ and $4.61 \%$, respectively. To check conversion of nitrate to nitrite (recovery rate), predetermined amounts of nitrate were added to control plasma samples; these samples were deproteinized and reduced as above.

\section{HISTOPATHOLOGICAL EXAMINATION}

Histopathological evaluation was performed on kidney tissues. Paraffin-embedded specimens were cut into $6-\mu \mathrm{m}$ thickness sections and stained with hematoxylin \& eosin for examination under the light microscope using a conventional protocol (27) (BH-2; Olympus, Tokyo, Japan). A semi-quantitative evaluation of renal tissues was accomplished by scoring the degree of severity according to previously published criteria (28). All sections of kidney samples were examined for 
tubular necrosis. Briefly, a minimum of 50 proximal tubules associated with 50 glomeruli were examined for each slide and an average score was obtained. Severity of lesion was graded from 0 to 3 according to the percentage of tubular involvement. Slides were examined and assigned for severity of changes using scores on scale in which (0) denotes no change; grade (1) changes affecting $<25 \%$ tubular damage (mild); grade (2) changes affecting $25-50 \%$ of tubules (moderate); grade (3) changes affecting $>50 \%$ of tubules (severe).

Histopathological evaluation was performed on left kidney tissues. Paraffin-embedded specimens were cut into 5-mm thick sections and stained with hematoxylin \& eosin and Masson's trichrome for examination under the light microscope (BH-2; Olympus, Tokyo, Japan).

To evaluate leukocyte infiltration, the widening of interstitial spaces with focal leukocyte infiltration was assessed in five randomly chosen sections prepared from each kidney sample. For each section, the average number of leukocytes per $0.28 \mathrm{~mm}^{2}$ was calculated from these leukocyte-infiltrated foci using a high-power microscopic field (x400).

In order to estimate the grade of interstitial fibrosis, the interstitial area that stained green with Masson's trichrome was evaluated as a percentage of the total examined area in five randomly chosen sections prepared from each kidney sample using an image analyzer (Leica; Leica Micros Imaging Solutions, Cambridge, UK). For each section, interstitial space widening with focal leukocyte infiltration and interstitial fibrosis was assessed in high-power fields (x400) to quantify the results. The Banff classification of kidney pathology was used for scoring the degree of mononuclear cell infiltration and interstitial fibrosis. The score was graded from 0 to 3, depending on the severity of histological characteristics (29).

\section{Statistical analyses}

Results of all groups were shown as mean values \pm standard deviation (SD). Statistical analyses of the histopathologic evaluation of the groups were carried out by the Chi-square test and biochemical data were analyzed by the one-way analysis of variance (ANOVA). The significance between two groups was determined by the Dunnett's multiple comparison test, and $\mathrm{P}<0.05$ was accepted as statistically significant value.

\section{RESULTS}

There was no significant difference for urea-creatinine levels between groups (Table-1).

Tissue MDA levels significantly increased in Group-2 compared with Groups-1, 3, and 4 ( $\mathrm{p}<0.001$ ). Rats with ML administration (Group-4) showed reduced levels of lipid peroxidation as measured by MDA levels (Table-2). UUO also induced a significant increase in the tissue NO levels that have been prevented by ML (Table-2). The unilateral ureteral ligation was accompanied by a marked reduction in GSH level in the kidney tissues of rats $(\mathrm{p}<0.001)$, and treatment with $\mathrm{ML}$ partially elevated the GSH levels (Table-2).

Histopathologic examination was normal in rats with only sham operation (Group-3) and in rats with no operation (Group-1) (Figures 1A and B). In rats with UU0, there were mild and severe tubular necrosis in the proximal tubules compared control and sham groups (Figure-1C). In rats treated with UUO+ML, despite the presence of mild

Table 1 - Effects of UO alone and its combination with ML on plasma urea, creatinine levels in rats.

\begin{tabular}{lcccc}
\hline Parameters & Control & Sham & U0 & U0+ML \\
\hline Urea $(\mathrm{mg} / \mathrm{dL})$ & $34 \pm 8.1$ & $35.5 \pm 8.6$ & $37.5 \pm 10.6$ & $36.1 \pm 8.1$ \\
Creatinine $(\mathrm{mg} / \mathrm{dL})$ & $0.44 \pm 0.1$ & $0.47 \pm 0.2$ & $0.51 \pm 0.2$ & $0.48 \pm 0.1$ \\
\hline
\end{tabular}

Values are expressed as mean \pm SD for eight rats in each group. 
tubular degeneration and less severe tubular necrosis, glomeruli maintained a better morphology when compared with UUO group (Figure-1D). Severe leukocyte infiltration was observed in the periglomerular and peritubular interstitium of the kidneys of the rats in group-2 with UUO (Figures $2 \mathrm{~A}$ and $\mathrm{B})$.

Quantitative analysis of the focal leukocyte infiltration area in the interstitium showed that leukocyte infiltration was significantly reduced in rats that received UU0+ML (Group-4) (Figure-2C). UUO caused a significant interstitial fibrosis in rats that received no treatment (Group-2), and the percentage area of interstitial fibrosis in the kidney of rats with UUO that received no treatment was significantly greater than that of rats with UUO that received ML (Group-4) (Figures 3A, B and $\mathrm{C})$. These changes are summarized in Table-3.

Table 2 - Effect of ML on the Levels of Malondialdehyde, Glutathione, and Nitric Oxide in Each Rat Group.

\begin{tabular}{lcccc}
\hline Parameters & Kontrol & Sham & UO & UO + MLS \\
\hline NO (nmol/g wet tissue) & $30.3 \pm 9.3$ & $30.3 \pm 10.2$ & $63.2 \pm 15.2^{\mathrm{a}}$ & $36.3 \pm 9.3^{\mathrm{b}}$ \\
MDA (nmol/g wet tissue) & $2.6 \pm 0.7$ & $2.7 \pm 0.7$ & $5.1 \pm 1.2^{\mathrm{a}}$ & $2.9 \pm 0.9^{\mathrm{b}}$ \\
GSH (umol/g wet tissue) & $2.3 \pm 0.8$ & $2.2 \pm 0.7$ & $1.1 \pm 0.5^{\mathrm{c}}$ & $2.1 \pm 0.7^{\mathrm{d}}$ \\
\hline
\end{tabular}

Values are expressed as mean \pm SD for eight rats in each group.

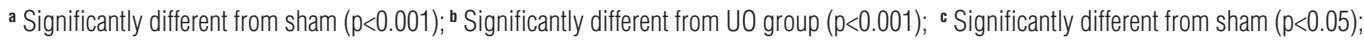

¿Significantly different from U0 group $(p<0.05)$.

Abbreviations: $\mathbf{N O}$ = nitric oxide; $\mathbf{M D A}=$ malondialdehyde; $\mathbf{G S H}$ = reduced glutathione.

Figure 1- $\mathrm{A}=$ normal tubulus and glomerules in kidney kortex H\&Ex100 (control group). $\mathrm{B}=$ normal tubulus and glomerules in kidney kortex H\&Ex100 (sham group). C = severe tubular necrosis, tubular degeneration and epithelial vacuolization in the proximal tubules H\&Ex100(UUO group). $D=$ mild epithelial vacuolization in the proximal tubules and normal glomerules H\&Ex100 (UUO+ML treated group).
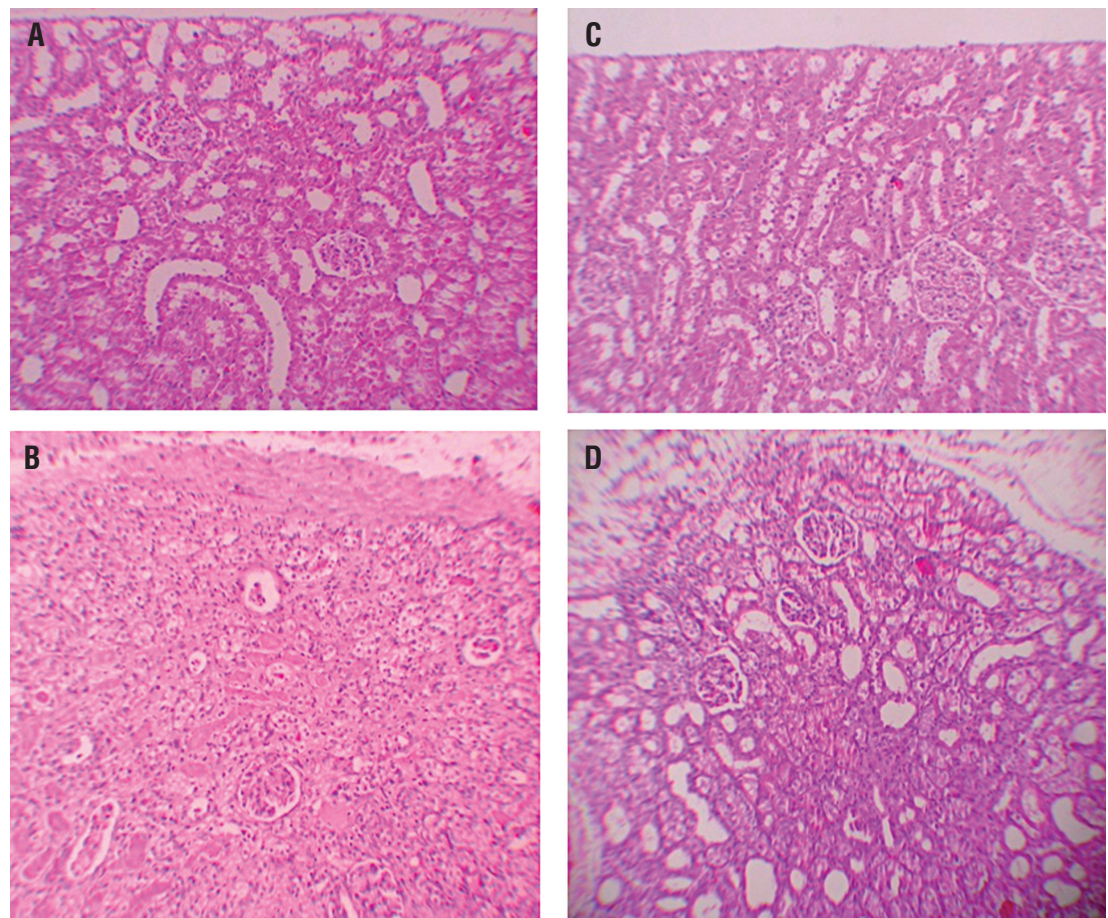
Figure $2-A=$ Normal kidney morphology in a sham group. $B=$ Leukocyte infiltration was observed in the peritubular interstitium of the UUO. C = Leukocyte infiltration was reduced in the ML-treated group (hematoxylin \& eosin, ${ }^{*} 400$ ).

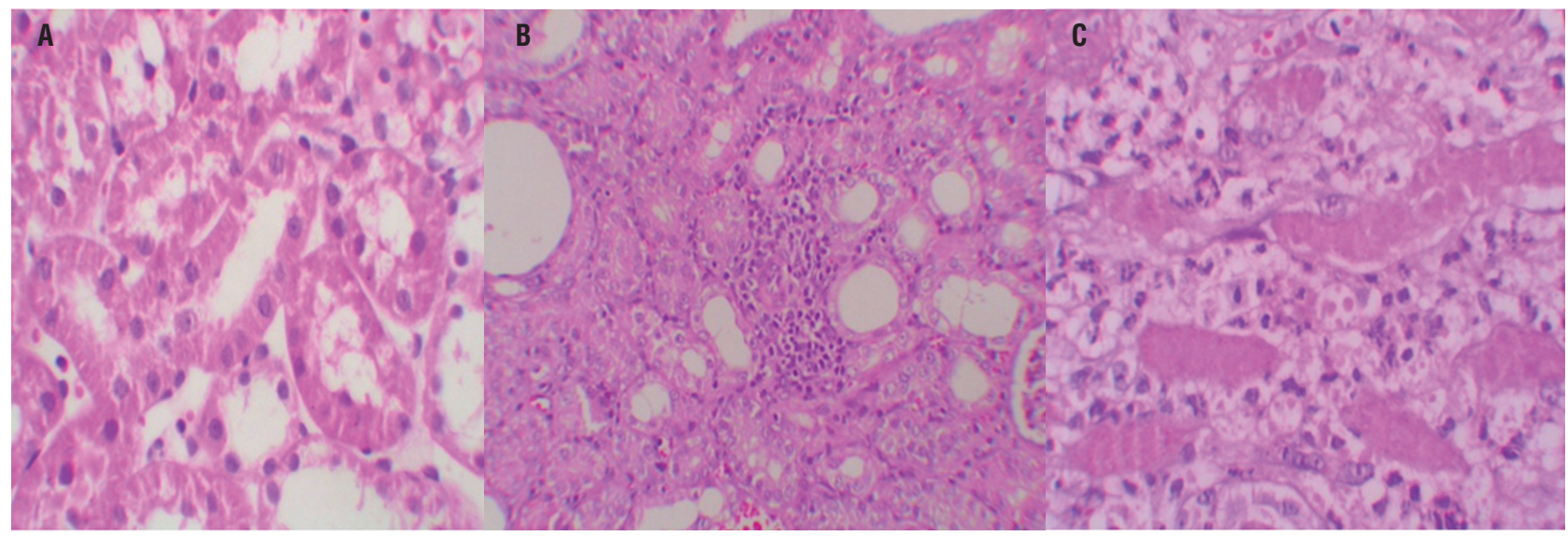

Figure $3-A=$ Normal kidney morphology in a sham group. $B=$ severe fibrosis was observed in the peritubular interstitium of the UUO. C = mild fibrosis was reduced in the ML-treated group (masson \& trichrome, ${ }^{*} 400$ ).

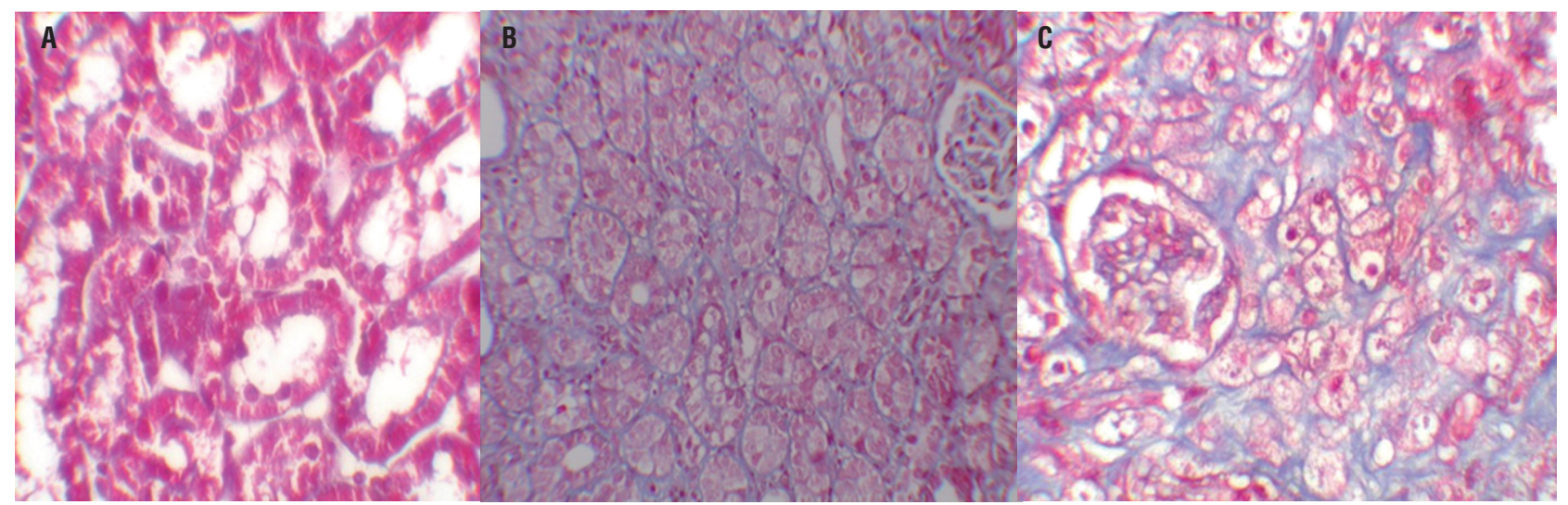

Table 3 - Semiquantitative analysis of tubular necrosis, interstitial fibrosis, mononuclear cell infiltration in control, Sham, $\mathrm{UO}$, and $\mathrm{U} 0+\mathrm{ML}$ treated rats.

\begin{tabular}{|c|c|c|c|c|c|c|c|c|c|c|c|c|c|}
\hline & \multicolumn{5}{|c|}{ Tubular necrosis } & \multicolumn{4}{|c|}{ Interstitial fibrosis } & \multicolumn{4}{|c|}{ Mononuclear cell infiltration } \\
\hline & $\mathrm{n}$ & 0 & 1 & 2 & 3 & 0 & 1 & 2 & 3 & 0 & 1 & 2 & 3 \\
\hline Control & 8 & 8 & 0 & 0 & 0 & 8 & 0 & 0 & 0 & 7 & 1 & 0 & 0 \\
\hline Sham & 8 & 8 & 0 & 0 & 0 & 8 & 0 & 0 & 0 & 7 & 1 & 0 & 0 \\
\hline UOa & 8 & 0 & 1 & 4 & 3 & 0 & 2 & 3 & 3 & 0 & 2 & 2 & 4 \\
\hline $\mathrm{UO}+\mathrm{ML}^{\mathrm{b}}$ & 8 & 1 & 5 & 1 & 1 & 2 & 5 & 1 & 0 & 1 & 6 & 1 & 0 \\
\hline
\end{tabular}

Score 0 = no degeneration, 1 = mild degeneration, 2 = moderate degeneration, and 3 = severe degeneration

a Statistical significant difference from the Sham group

b Statistical significant difference from the U0 group and $\mathrm{P}<0.05$ 


\section{DISCUSSION}

The present study confirmed through a quantitative survey the protective role of ML on renal tissue damage after the induction of UUO in rats. Our results showed that the obstructed kidney had significantly higher tissue MDA, NO levels, and lower GSH levels along with more fibrosis. The current data demonstrate UUO structural and functional alterations in the kidney with a concomitant increase in proinflammatory cytokines in the blood. The CysLT1 receptor antagonist montelukast, on the other hand, reduced the severity of injury, depressed the concentration of these cytokines and increased the antioxidative capacity.

Montelukast, one of the selective reversible CysLT1 receptor antagonists, is used for the maintenance treatment of asthma and to relieve symptoms of seasonal allergies(30). It is reported that montelukast can reduce eosinophilic inflammation in the airways (31-33).

Besides, CysLT1 receptor antagonists or biosynthesis inhibitors ameliorate ethanol-induced gastric mucosal damage $(13,34)$, experimental colitis (35), and wound healing $(36,37)$.

Recently, Sener et al. (22) have reported that montelukast has protective effects on chronic renal failure-induced multiple organ injury. They attributed this to montelukast's ability to inhibit neutrophil infiltration and apoptosis. They also suggested that montelukast balances the oxidantantioxidant status and regulates the generation of proinflammatory mediators. In a different study, it has been shown that montelukast reversed ischemia reperfusion-induced oxidant responses and improved microscopic damage and renal functions (31).

Apoptotic cell death has been reported to play an important role in UUO-induced renal damages (38). The lack of investigation on whether ML has affected the apoptotic cell death because of UUO may be a limitation of this study. However, in a recent study, curcumin and melatonine which is an antioxidant and antiinflammatory agent like ML, has been reported to prevent UUO-mediated apoptotic cell death and reduce the UUO related renal damage. While we believe that ML can reduce the UUO-induced renal damage by a similar mechanism that prevents apoptosis-related cell death, there is a need for further study on that subject for verifications.

The pathogenesis of renal fibrosis caused by UUO involves infiltration of the kidney by inflammatory cells including monocytes, activation and possible transformation of intrinsic renal cells, and interactions between infiltrating and resident cells. NF-kB is activated during renal obstruction, and inhibition of NF-kB activity has been demonstrated to prevent renal fibrosis induced by obstruction $(39,40)$. In the present study, in agreement with these findings, ML treatment prevented renal fibrosis in UUO rats.

In obstructive nephropathy, it is known that particularly by treatment of UUO, some functions of the kidney can be regained. However, by recovery from the ureteral obstruction, reperfusion damage may occur in the renal tissue as a result of the elevated renal blood flow.

Ischemia-reperfusion (IR) injury is one of the underlying causes of acute renal failure and ROS along with NO, and it plays important roles in mediating cell damage during IR injury (41, 42). Inflammatory cells, neutrophils, are potent cells for production of ROS that are highly produced during IR injury. Renal IR causes tissue injury by way of oxygen radicals and disturbs balance between oxidants and antioxidants in tissue (43). Rodriguez-Reynoso et al. found that exogenous melatonine (MLT) preserved renal function, increased GSH levels, reduced lipid peroxidation, and prevented the rise in NO levels induced by renal IR (44).

They also indicated that MLT treatment reduced histological kidney injury. In accordance with the increase in toxic oxygen metabolites, the renal MDA level was also significantly increased, indicating the presence of enhanced lipid peroxidation due to IR injury, while the levels of tissue glutathione were declined, demonstrating the depletion of the antioxidant pool.

Several studies have demonstrated that IR in the kidney is associated with lipid peroxidation, which is an autocatalytic mechanism leading to oxidative destruction of cellular membranes (4547). As montelukast reduced the oxidative injury on cellular structures, the level of the intracellu- 
lar antioxidant glutathione, which is otherwise oxidized when inactivating free radicals, was not changed. Thus, it appears that the anti-oxidative effect of montelukast on lipid peroxidation does not involve the expenditure of tissue GSH stores, but the antioxidant pool is further supported by the action of montelukast. Moreover, IR-induced reduction in total antioxidant capacity was also reversed by montelukast treatment (31).

As shown in our study, ML has a protective role against both renal damage arising because of UUO and the reperfusion damage occurring as a result of the treatment of obstruction that gives way to elevated renal blood flow.

In conclusion, the results reported here indicate that ML exerts a preventive effect on UU0-induced kidney damage in rats by reducing oxidative stress. We therefore propose that ML supplementation therapy can be used for kidney protection in patients with UUO, such as ureteral stones. Hovewer, further animal and clinical studies are needed to confirm our suggestion.

\section{CONFLICT OF INTEREST}

None declared.

\section{REFERENCES}

1. Sato S, Yamate J, Saito T, Hosokawa T, Saito S, Kurasaki M. Protective effect of taurine against renal interstitial fibrosis of rats induced by cisplatin.Naunyn Schmiedebergs Arch Pharmacol. 2002;365:277-83.

2. Vaughan ED Jr, Sorenson EJ, Gillenwater JY. The renal hemodynamic response to chronic unilateral complete ureteral occlusion. Invest Urol. 1970;8:78-90.

3. Schreiner GF, Harris KP, Purkerson ML, Klahr S. Immunological aspects of acute ureteral obstruction: immune cell infiltrate in the kidney. Kidney Int. 1988;34:48793.

4. Ricardo SD, Ding G, Eufemio M, Diamond JR. Antioxidant expression in experimental hydronephrosis: role of mechanical stretch and growth factors. Am J Physiol. 1997;272:F789-98.

5. Saborio P, Krieg RJ Jr, Kuemmerle NB, Norkus EP, Schwartz CC, Chan JC. Alpha-tocopherol modulates lipoprotein cytotoxicity in obstructive nephropathy. Pediatr Nephrol. 2000;14:740-6.
6. Kawada N, Moriyama T, Ando A, Fukunaga M, Miyata T, Kurokawa $\mathrm{K}$, et al. Increased oxidative stress in mouse kidneys with unilateral ureteral obstruction. Kidney Int. 1999;56:1004-13.

7. Klahr S. Urinary tract obstruction. Semin Nephrol. 2001;21:133-45.

8. Huang HS, Ma MC, Chen CF, Chen J. Changes in nitric oxide production in the rat kidney due to $\mathrm{CaOx}$ nephrolithiasis. Neurourol Urodyn. 2006;25:252-8.

9. Aviram M, Dornfeld L, Rosenblat M, Volkova N, Kaplan $\mathrm{M}$, Coleman $\mathrm{R}$, et al. Pomegranate juice consumption reduces oxidative stress, atherogenic modifications to LDL, and platelet aggregation: studies in humans and in atherosclerotic apolipoprotein E-deficient mice. Am J Clin Nutr. 2000;71:1062-76.

10. Schubert SY, Neeman I, Resnick N. A novel mechanism for the inhibition of NF-kappaB activation in vascular endothelial cells by natural antioxidants. FASEB J. 2002;16:1931-3.

11. Aviram M, Dornfeld L, Kaplan M, Coleman R, Gaitini D, Nitecki S, et al. Pomegranate juice flavonoids inhibit lowdensity lipoprotein oxidation and cardiovascular diseases: studies in atherosclerotic mice and in humans. Drugs Exp Clin Res.2002;28:49-62.

12. Wallace JL, MacNaughton WK, Morris GP, Beck PL. Inhibition of leukotriene synthesis markedly accelerates healing in a rat model of inflammatory bowel disease. Gastroenterology. 1989;96:29-36.

13. Wallace JL, McKnight GW, Keenan CM, Byles NI, MacNaughton WK. Effects of leukotrienes on susceptibility of the rat stomach to damage and investigation of the mechanism of action. Gastroenterology. 1990;98:117886.

14. Wallace JL, Beck PL, Morris GP. Is there a role for leukotrienes as mediators of ethanol-induced gastric mucosal damage? Am J Physiol. 1988;254:G117-23.

15. Damon M, Chavis C, Godard P, Michel FB, Crastes de Paulet A. Purification and mass spectrometry identification of leukotriene D4 synthesized by human alveolar macrophages. Biochem Biophys Res Commun. 1983 Mar 16;111:518-24.

16. Williams JD, Czop JK, Austen KF. Release of leukotrienes by human monocytes on stimulation of their phagocytic receptor for particulate activators. J Immunol.1984 Jun;132:3034-40.

17. Aharony D. Pharmacology of leukotriene receptor antagonists . Am J Respir Crit Care Med. 1998;157:S2149.

18. O'Byrne PM. Asthma treatment: antileukotriene drugs. Can Respir J. 1998;5 Suppl A:64A-70A.

19. Wenzel SE. Leukotriene receptor antagonists and related compounds. Can Respir J. 1999;6:189-93. 
20. Carsin H, Bargues L, Stéphanazzi J, Paris A, Aubert P, Le Béver $H$. [Inflammatory reaction and infection in severe burns]. Pathol Biol (Paris). 2002;50:93-101.

21. Konturek SJ, Brzozowski T, Drozdowicz D, Beck G. Role of leukotrienes in acute gastric lesions induced by ethanol, taurocholate, aspirin, platelet-activating factor and stress in rats. Dig Dis Sci. 1988;33:806-13.

22. Sener G, Sakarcan A, Sehirli 0, Ekşioğlu-Demiralp E, Sener $\mathrm{E}$, Ercan $\mathrm{F}$, et al. Chronic renal failure-induced multiple-organ injury in rats is alleviated by the selective CysLT1 receptor antagonist montelukast. Prostaglandins Other Lipid Mediat. 2007;83:257-67.

23. Wasowicz $W$, Nève J, Peretz A. Optimized steps in fluorometric determination of thiobarbituric acid-reactive substances in serum: importance of extraction $\mathrm{pH}$ and influence of sample preservation and storage. Clin Chem. 1993;39:2522-6.

24. Moron MS, Depierre JW, Mannervik B. Levels of glutathione, glutathione reductase and glutathione S-transferase activities in rat lung and liver. Biochim Biophys Acta. 1979;582:67-78.

25. Lowry $\mathrm{OH}$, Rosebrough $\mathrm{NJ}$, Farr AL, Randall RJ. Protein measurement with the Folin phenol reagent. J Biol Chem. 1951;193:265-75.

26. Granger DL, Taintor RR, Boockvar KS, Hibbs JB Jr. Measurement of nitrate and nitrite in biological samples using nitrate reductase and Griess reaction. Methods Enzymol. 1996;268:142-51.

27. Sun Y, Oberley LW, Li Y. A simple method for clinical assay of superoxide dismutase. Clin Chem. 1988;34:497-500.

28. Allen CT. Laboratory methods in histochemistry. In: Prophet EB, Mills B, Arrington JB, Sobin LH (eds). American registry of pathology, 1st edn. Washington DC. 1992; pp. 53.

29. Kinugasa F, Noto T, Matsuoka H, Urano Y, Sudo Y, Takakura $S$, et al. Prevention of renal interstitial fibrosis via histone deacetylase inhibition in rats with unilateral ureteral obstruction. Transpl Immunol. 2010;23:18-23.

30. Canbay E, Agachan B, Ozturk T, Giris M, Asoglu 0, Balik E, et al. Dual inhibition of wound healing and oxidative process by montelukast in experimental colon anastomoses. Surg Innov. 2010;17:248-55.

31. Sener G, Sehirli 0, Velioğlu-Oğünç A, Cetinel S, Gedik N, Caner M, et al. Montelukast protects against renal ischemia/ reperfusion injury in rats. Pharmacol Res. 2006;54:65-71.

32. Damtew B, Marino JA, Fratianne RB, Spagnuolo PJ. Neutrophil lipoxygenase metabolism and adhesive function following acute thermal injury. J Lab Clin Med. 1993;121:328-36.

33. Wallace JL, Beck PL, Morris GP. Is there a role for leukotrienes as mediators of ethanol-induced gastric mucosal damage? Am J Physiol. 1988;254(1 Pt 1):G117-23.

34. Carsin H, Bargues L, Stéphanazzi J, Paris A, Aubert P, Le Béver $H$. Inflammatory reaction and infection in severe burns. Pathol Biol (Paris). 2002;50:93-101.
35. Konturek SJ, Brzozowski T, Drozdowicz D, Beck G. Role of leukotrienes in acute gastric lesions induced by ethanol, taurocholate, aspirin, platelet-activating factor and stress in rats. Dig Dis Sci. 1988;33:806-13.

36. Kabasakal L, Sener G, Cetinel S, Contuk G, Gedik N, Yeğen BC. Burn-induced oxidative injury of the gut is ameliorated by the leukotriene receptor blocker montelukast. Prostaglandins Leukot Essent Fatty Acids. 2005;72:431-40.

37. Turtay MG, Firat C, Samdanci E, Oguzturk H, Erbatur S, Colak C. Effects of montelukast on burn wound healing in a rat model. Clin Invest Med. 2010;33:E413-21.

38. Hashem RM, Soliman HM, Shaapan SF. Turmeric-based diet can delay apoptosis without modulating NF-kappaB in unilateral ureteral obstruction in rats. J Pharm Pharmacol. 2008;60:83-9.

39. Cheung RT, Tipoe GL, Tam S, Ma ES, Zou LY, Chan PS. Preclinical evaluation of pharmacokinetics and safety of melatonin in propylene glycol for intravenous administration. J Pineal Res. 2006;41:337-43.

40. Pignone AM, Rosso AD, Fiori G, Matucci-Cerinic M, Becucci $A$, Tempestini $A$, et al. Melatonin is a safe and effective treatment for chronic pulmonary and extrapulmonary sarcoidosis. J Pineal Res. 2006;41:95-100.

41. Basireddy M, Isbell TS, Teng X, Patel RP, Agarwal A. Effects of sodium nitrite on ischemia-reperfusion injury in the rat kidney. Am J Physiol Renal Physiol.2006;290:F779-86

42. Noiri E, Nakao A, Uchida K, Tsukahara H, Ohno M, Fujita T, et al. Oxidative and nitrosative stress in acute renal ischemia. Am J Physiol Renal Physiol. 2001;281:F948-57.

43. Erdogan $\mathrm{H}$, Fadillioglu E, Yagmurca $\mathrm{M}$, Uçar M, Irmak MK. Protein oxidation and lipid peroxidation after renal ischemiareperfusion injury: protective effects of erdosteine and N-acetylcysteine. Urol Res. 2006;34:41-6.

44. Rodríguez-Reynoso S, Leal C, Portilla-de Buen E, Castillo JC, Ramos-Solano F. Melatonin ameliorates renal ischemia/ reperfusion injury. J Surg Res. 2004;116:242-7.

45. Singh D, Chander V, Chopra K. Carvedilol attenuates ischemia-reperfusion-induced oxidative renal injury in rats. Fundam Clin Pharmacol. 2004;18:627-34.

46. Singh D, Chopra K. Effect of trimetazidine on renal ischemia/ reperfusion injury in rats. Pharmacol Res. 2004;50:623-9. Retraction in: Pharmacol Res. 2008;57:476.

47. Eschwège $P$, Paradis V, Conti $M$, Holstege $A$, Richet $F$, Detève J, et al. In situ detection of lipid peroxidation by-products as markers of renal ischemia injuries in rat kidneys. J Urol. 1999;162:553-7.

Correspondence address: Alper Otunctemur, MD Okmeydani Training and Research Hospital Department of Urology 34384, Sisli, Istanbul, Turkey Fax: +90 212 314-5503 E-mail: alperotunctemur@yahoo.com 